\title{
O Mal-Estar na Modernidade e a Psicanálise: a Psicanálise à Prova do Social $^{1}$
}

\author{
JOEL BIRMAN²
}

O artigo tem a intenção de indicar a presença de dois discursos teóricos opostos em Freud, no que concerne às relações entre sujeito e modernidade. Pretende-se demonstrar que na sua segunda versão, desenvolvida em $\mathrm{Mal}$ estar na civilização, o discurso psicanalítico realizou uma crítica sistemática de sua versão inicial, esboçada em "Moral sexual' civilizada' e a doença nervosa dos tempos modernos". Pela construção dos conceitos de desamparo e de mal-estar, o discurso freudiano colocou então a psicanálise à prova do social. Além disso, indica que aquela pôde construir uma leitura sobre a modernidade, ao lado das que foram realizadas por Weber e Heidegger. Finalmente, esse percurso tem ainda a finalidade de pensar a crise da psicanálise na atualidade, nas novas condições do mal-estar na modernidade.

Palavras-chave: Mal-estar; desamparo; sublimação. 


\section{Os Discursos Freudianos sobre o Social}

A modernidade e seus impasses são a problemática fundamental deste ensaio. Temos a intenção de trabalhá-la sob a perspectiva teórica da psicanálise, na medida em que esta tematizou, com Freud, não apenas a modernidade enquanto tal, mas também as impossibilidades construídas para o sujeito naquela. Isso implica dizer que os discursos forjados por Freud para enunciar a questão da subjetividade no campo da civilização, no sentido universalista desta última, foram na verdade comentários tecidos sobre a condição do sujeito na modernidade. É preciso considerar essa especificidade na leitura freudiana sobre a civilização para dar a esta leitura toda a espessura de sua relatividade histórica e retirá-la, em contrapartida, do estatuto ingênuo de totalizações inconsistentes e abstratas. Portanto, é preciso explicitar que as interpretações freudianas sobre os impasses do sujeito no mundo da civilização constituem, de fato e de direito, comentários críticos sobre a inscrição do sujeito na modernidade.

No que tange a isso, Freud se deslocou entre dois pólos opostos que se contrapõem nos seus menores detalhes, como veremos ainda. Com efeito, se no começo de seu percurso teórico Freud acreditou na harmonia possível entre o registro do sujeito e o registro do social (FREUD, 1969, p. 28-46), em seguida, contudo, essa harmonia foi colocada incisivamente em questão, de maneira que a problemática do desamparo do sujeito no campo social foi a marca decisiva da leitura daquele sobre a inserção do sujeito na modernidade (FREUD, 1971). Pelo enunciado da condição de desamparo da subjetividade no novo espaço social, foi a desarmonia nos laços sociais então sublinhada por Freud. Com isso, o discurso freudiano assume um estilo trágico de leitura da modernidade.

Por esse viés, pode-se entrever que no segundo discurso freudiano sobre o social o discurso inicial foi colocado em questão de maneira radical. Isso quer dizer que, pelo seu discurso final sobre a modernidade, o pensamento psicanalítico colocou a psicanálise à prova do social, o que a obrigou então a se reconstituir sobre novas bases e outros fundamentos. Pode-se retomar, aqui, o segundo tópico desta discussão mais abrangente, qual seja, a colocação em questão do discurso psicanalítico pela categoria do social. Pretende-se sustentar a hipótese de trabalho de que a psicanálise foi colocada à prova do social quando nos deslocamos do discurso freudiano inicial sobre a modernidade para o discurso final sobre esta questão. 
Contudo, é preciso ainda evocar que quase nunca a tradição psicanalítica se manteve fiel ao deslocamento teórico operado no discurso freudiano. Em geral, aquela tradição misturava alguns fragmentos do último Freud com alguns dos conceitos do primeiro, de forma que a tese de que a psicanálise foi colocada decisivamente em questão pelo social foi esquecida e recalcada. Com isso, a fulgurância crítica do gesto teórico do último Freud foi colocada em suspensão e no limite conduzida ao silêncio. Isso quer dizer que nem sempre a tradição psicanalítica se mostrou condizente e à altura com a leitura crítica de Freud sobre a modernidade.

Tudo isso nos revela o conformismo crítico assumido pela tradição psicanalítica pós-freudiana. Ao silenciar a radicalidade da crítica freudiana sobre a modernidade, a psicanálise assumiu um tom ao mesmo tempo triunfalista e cientificista, incompatível com os argumentos radicais sobre o mal-estar na modernidade. A psicanálise não saiu indene, contudo, desse esquecimento e silêncio. Essa solução de compromisso lhe custou caro, pois algo da argúcia psicanalítica se perdeu, evidentemente. Com efeito, a psicanálise como discurso teórico perdeu suas dimensões ética e política, ficando restrita a uma mera perspectiva terapêutica na qual a harmonia do sujeito no campo social seria sua finalidade maior. Vale dizer, a psicanálise incorporou, assim, em seu corpo teórico, uma perspectiva normativa pela qual a medicalização do social pôde se realizar sem resistências, na medida em que foi silenciado o potencial crítico da tese sobre o mal-estar na modernidade.

Para que se possa bem avaliar esse desdobramento do pensamento psicanalítico, é preciso, contudo, considerar devidamente o novo lugar da psicanálise na atualidade, antes de qualquer coisa. Vale dizer, é preciso indicar a condição de crise da psicanálise naquilo que denominamos de novas condições do mal-estar na modernidade. Acreditamos que, dessa maneira, se pode entrever a contemporaneidade e a agudeza da questão que aqui levantamos, para que possamos, em seguida, retomar a oposição teórica que propusemos entre um discurso freudiano sobre a harmonia do sujeito no campo social e um outro, no qual o mal-estar e o desamparo estão em seu fundamento.

\section{A Configuração Atual dos Saberes sobre o Psíquico}

A questão da crise da psicanálise está na ordem do dia em todos os lugares, principalmente nos Estados Unidos e em alguns países europeus, mas também, de outra maneira, na América Latina. A crise não se configura da 
mesma forma nas diferentes formações sociais onde se constituiu um movimento psicanalítico, evidentemente. Com efeito, as diferenças nas formas de ser dessa crise são, muitas das vezes, mais importantes que as similitudes, sem dúvida.

Pode-se atribuir essa diversidade evidente aos diferentes processos de modernização do social que marcaram as múltiplas formações sociais onde se inscreveu a tradição psicanalítica. Nessa perspectiva, é óbvia a decalagem entre crise da psicanálise nos Estados Unidos e na França, e a que existe agora na América Latina. De forma complementar, considerando agora apenas os países europeus, o estatuto atual do movimento psicanalítico na Espanha, em Portugal e nos países do Leste Europeu, não é similar ao que acontece, hoje, na França e na Inglaterra (BIRMAN, 1996). Enfim, os diferentes ritmos e temporalidades que marcaram o processo histórico de modernização do social nos permitem explicar devidamente tais diversidades ${ }^{3}$.

Entretanto, apesar dessas diferenças óbvias e eloqüentes, pode-se enunciar a existência de uma crise da psicanálise na atualidade. Não obstante tais diferenças, a tese sobre a crise atual do discurso psicanalítico se mostra consistente e legítima. Pode-se indicar isso de diferentes maneiras, pela utilização de múltiplos critérios de leitura, que sinalizam tal processo histórico-social tanto no âmbito do imaginário social contemporâneo quanto no lugar ocupado pela psicanálise no campo dos saberes sobre o psiquismo na atualidade. Pela articulação cerrada desses dois critérios, pode-se compreender as transformações atuais no campo da demanda clínica.

Com efeito, a psicanálise assume cada vez mais a condição de estrangeira no mundo da atualidade. Enquanto estrangeira, aquela se torna uma estranha. Pode-se indicar essa transformação significativa desde o início dos anos 80 na França, se bem que o processo começou bem mais cedo nos Estados Unidos, desde o início dos anos 60 (CASTEL, CASTEL \& LOVELL, 1979). Nesse contexto, a psicanálise não fascina mais as pessoas como outrora. Sendo um dos mitos da modernidade, pelo menos desde os anos 30, a psicanálise perdeu o seu lugar de destaque na cena do social. Com isso, a psicanálise parou de produzir barulho e de ser uma fonte de irrupção no social como se passava anteriormente. Enfim, seria por causa disso que a psicanálise passou a se configurar ao mesmo tempo como estrangeira e estranha no campo social da atualidade.

Pode-se mostrar a banalidade disso de diferentes maneiras, como já disse, indicando a evidência desse processo no registro prático e no registro 
teórico. No registro prático, pode-se reconhecer com facilidade a diminuição vertiginosa que se realizou no nível da demanda para a cura psicanalítica. A demanda clínica diminuiu de maneira significativa, segundo reconhecem os analistas em geral. Em contrapartida, as pessoas tendem a preferir os tratamentos psicofarmacológicos e as psicoterapias de curta duração. Estas se definem, em geral, pelo tempo estabelecido previamente no contrato estabelecido pelo psicoterapeuta e pelo paciente. Além disso, multiplicam-se as psicoterapias de grupo, de família e de casal, numa escala significativa.

No registro teórico, de maneira complementar, os modelos advindos do cognitivismo fascinam cada vez mais o campo dos saberes do psíquico e as ciências humanas num sentido mais geral. Tudo isso, evidentemente, no lugar das hipóteses psicanalíticas. Estas são substituídas progressivamente por aqueles. Além disso, os modelos das neurociências impregnam de maneira crescente os saberes do psiquismo, silenciando e deslocando para a periferia do campo teórico do psiquismo as teorias psicanalíticas.

Com efeito, se até o final dos anos 70 a psicanálise era o discurso de referência no campo dos saberes sobre o psíquico e ocupava, como sabemos, lugar estratégico no campo das ciências humanas, cada vez mais aquela perde essa posição de privilégio. Assim, a psicanálise perdeu não apenas a posição estratégica que ocupava no campo dos saberes sobre o psíquico, sendo substituída paulatinamente pela psiquiatria biológica, pelo discurso das neurociências e pelas teorias do cognitivismo, mas também seu lugar primordial de referência no campo das Ciências Humanas.

Como se pode depreender, estamos no centro de duas problemáticas aqui em questão, isto é, o sujeito na modernidade e o sujeito à prova do social. A indagação que se impõe é sobre o que se passou nesse conjunto de transformações cruciais, cuja resultante maior foi a perda de poder simbólico da psicanálise no campo dos saberes sobre o psíquico e no imaginário social da modernidade. É a isso que temos que responder, ou, pelo menos, esboçar um caminho possível de resposta para nos aproximarmos de uma interpretação que seja consistente sobre a crise da psicanálise na atualidade e de uma leitura sobre as novas condições do mal-estar na modernidade.

Para responder de maneira consistente, é preciso circunscrever previamente o lugar estratégico ocupado pela psicanálise no imaginário da modernidade. Para isso, é preciso retomar o ensaio freudiano sobre o mal-estar na civilização na medida em que as hipóteses de trabalho deste texto nos 
permitam pensar, em contrapartida, no lugar da modernidade no imaginário teórico da psicanálise, no sentido ao mesmo tempo epistemológico e político. Pode-se vislumbrar, assim, as duas faces de uma mesma problemática já que, pela primeira versão, pretende-se conferir à modernidade a posição de referência maior em torno da qual se inscreve a psicanálise, enquanto pela segunda versão trata-se de circunscrever a psicanálise como ponto de. vista sobre a modernidade. Tal é o propósito que pretendemos encaminhar sob a forma de um esboço teórico e para delinear uma direção de leitura.

Contudo, para retomar a leitura freudiana sobre o mal-estar na civilização, é preciso contrapô-la àquela que Freud realizou no início de seu percurso, justamente em 1908, em "A moral sexual 'civilizada' e a doença nervosa dos tempos modernos" (FREUD, 1969), já que podemos surpreender duas interpretações totalmente opostas sobre a inserção do sujeito na modernidade. Com isso, pode-se sublinhar como o discurso psicanalítico se colocou à prova do social, sendo obrigado a se reconstituir sobre novas bases.

\section{Entre Harmonia e Desarmonia}

Pode-se perguntar, logo de início, o que é que autoriza teoricamente esta comparação, afinal das contas? Como disse, os dois textos trabalham sobre a mesma temática, sem dúvida, e isso torna legítima a comparação. Com efeito, o que está em pauta é o conflito no sujeito entre o registro da pulsão e o registro da civilização. Entretanto, como já afirmado acima, as respostas de Freud são totalmente opostas. É justamente isso que torna fascinante a leitura comparativa desses ensaios.

Assim, na primeira versão freudiana sobre essa problemática foi enunciada a hipótese de que a psicanálise poderia oferecer uma resposta resolutiva ao mal-estar na civilização, enquanto na segunda versão essa resposta cortante e absoluta foi interrogada, isto é, a primeira versão freudiana foi colocada em questão. Por causa disso mesmo é que o último Freud foi considerado um pensador trágico, tanto pelos seus contemporâneos quanto pela posteridade; enquanto no começo de seu percurso aquele se mostrava totalmente confiante nos poderes da psicanálise. Portanto, algo de fundamental se processou entre 1908 e 1929 para que se produzisse essa transformação radical de perspectivas na leitura freudiana sobre a inscrição do sujeito na civilização. É necessário se aproximar docemente disso tudo para indicar as oposições em pauta de maneira 
precisa. Antes de mais nada, como já disse acima, o que está em questão nos dois ensaios é a relação entre o registro da pulsão e o da civilização. Essa relação foi sempre pensada, por Freud, como sendo da ordem do conflito. Quanto a isso, não existe qualquer dúvida.

Entretanto, no texto de 1908 esse conflito foi representado sob a forma de uma solução possível, isto é, de uma harmonia a ser conquistada entre os dois pólos de opostos pela mediação da psicanálise. Com efeito, a psicanálise poderia oferecer ensinamentos consistentes sobre a natureza da pulsão sexual e sobre a inserção desta na economia subjetiva, de maneira tal que o sujeito poderia alcançar uma certa relação tranqüila entre a exigência da pulsão e a exigência da civilização.

Em 1929, no entanto, Freud não acreditava mais nisso, de maneira que a relação conflitual entre a pulsão e a civilização seria de ordem estrutural, isto é, o conflito não seria jamais ultrapassado. Contudo, a maneira de encarar esse conflito, de manejá-lo, se transformou aos olhos de Freud. Se na versão inicial o conflito poderia ser curável, digamos assim, na versão final seria necessária uma espécie de gestão interminável e infinita do conflito pelo sujeito, de forma tal que este não poderia jamais se deslocar da sua posição originária de desamparo. Nesse deslocamento crucial entre o registro da terapêutica possível para o registro da gestão, pode-se vislumbrar que o discurso freudiano assume uma perspectiva ética e política sobre o conflito em questão.

Seria, pois, o destino possível a ser oferecido para o desamparo do sujeito que está no fundamento das diferenças entre as duas versões constituídas pelo discurso freudiano. Na primeira solução, com efeito, o sujeito poderia ultrapassar o seu desamparo pelo domínio seguro das pulsões sexuais. Para isso, o discurso freudiano construiu um conceito específico, que nomeou de sublimação. Pela mediação desta existiria uma transformação do registro do sexual naquele do não-sexual, pela transformação do alvo da pulsão sexual (FREUD, 1969, p. 33-34). Contudo, mesmo enunciando o conceito de sublimação dessa maneira, o discurso freudiano indica ao mesmo tempo uma série de contradições decorrentes dessa via para pensar a sublimação, já que assim o sujeito seria empobrecido não apenas do ponto de vista erótico mas também simbólico (FREUD, 1969, p. 37-46). Com isso, existiria um duplo handicap da sublimação sobre o sujeito. Além disso, aquilo que a sublimação deveria resolver, isto é, possibilitar um acesso enriquecedor para a subjetividade no registro da civilização, não se alcançaria, pois o sujeito eroticamente empobrecido seria também fraturado no registro simbólico. 
Entretanto, na sua segunda versão o discurso freudiano não acreditava mais nessas certezas iniciais, pois o sujeito não poderia se deslocar jamais de sua posição originária de desamparo. Pensar na irredutibilidade dessa posição, no entanto, não implica dizer que o sujeito deve existir necessariamente com perturbações do espírito, sejam estas da ordem da neurose, da psicose ou da perversão. Não se trata disso, absolutamente. Em contrapartida, enunciar a irredutibilidade do desamparo implica reconhecer que o sujeito deve fazer um trabalho infinito de gestão daquela, justamente porque o desamparo originário da subjetividade seria incurável. Pode-se dizer, enfim, de maneira indubitável, que o discurso freudiano acreditava, na sua versão primeira, que o desamparo poderia ser curável pela psicanálise, mas que na sua última versão essa crença se mostrava insustentável, ingênua e presunçosa.

Para melhor circunscrever a problemática do desamparo e sua incurabilidade, o discurso freudiano forjou diversos conceitos, de maneira progressiva, desde 1920. Pela construção desses conceitos, a direção da pesquisa psicanalítica do desamparo pôde tornar-se mais consistente, na medida em que Freud se deslocou do registro mais abstrato para o mais concreto. Com efeito, nessa circunscrição e deslocamento o discurso freudiano se movimentou entre o pólo da metapsicologia e o pólo da clínica, de maneira que a materialidade do desamparo foi-se delineando de forma mais patente na subjetividade.

Esses conceitos freudianos são bastante conhecidos na tradição psicanalítica, se bem que nem sempre aqueles tenham sido articulados por esta na problemática do desamparo. Assim, tanto pelo enunciado da pulsão de morte (FREUD, “Au-delà...", 1995), em 1920, quanto pela formulação dos conceitos de angústia do real (FREUD, "Inhibition...", 1973), em 1926, e de feminilidade (FREUD, "L' analyse...", 1986), em 1937, era sempre a questão do desamparo que estava em pauta.

Em contrapartida, esse campo de novos conceitos que podem balizar a problemática do desamparo foi a condição de possibilidade para a emergência de um outro conceito de sublimação, que se contrapõe radicalmente ao primeiro. Assim, para superar as contradições e os impasses colocados pelo conceito inicial de sublimação, o discurso freudiano enunciou, em 1932, que existiria a constituição de um outro objeto para a pulsão (FREUD, 1984), isto é, Freud não se manteria inalterado como na versão primeira do conceito. Isso significa que, na nova versão, não existiria mais oposição entre sexualidade e sublimação. Encontra-se justamente aqui a grande novidade. Vale dizer, existiria uma outra 
economia do erotismo na sublimação. Com isso, portanto, o processo de sublimação consistiria na transformação da pulsão de morte em pulsão sexual, de maneira tal que o erotismo e o trabalho de criação se tornariam possíveis. Pode-se dizer que os destinos do erotismo e da sublimação foram articulados de maneira cerrada no último discurso freudiano. Além disso, dominar o desamparo e não curá-lo quer dizer agora que é necessário para o sujeito constituir destinos tanto eróticos quanto sublimatórios para a pulsão. A tessitura desses destinos, em ambos os sentidos referidos, constituiu para o sujeito aquilo que denominamos há pouco de gestão do desamparo.

A gestão do desamparo toma uma direção bem precisa para o sujeito, diferente da versão freudiana inicial sobre a sublimação. Nessa versão, a sublimação era uma experiência de espiritualização, de ascese, pela qual a subjetividade seria purificada de seu erotismo perturbador. A sublimação aqui seria uma experiência de verticalização, desprendendo-se o sujeito de sua corporeidade animal e alçando-se aos pináculos da razão civilizatória. Contudo, em sua segunda versão, a sublimação não é um ato de espiritualização, mas de lateralização, não se desprendendo o sujeito do seu registro corpóreo. Pelo contrário, a sublimação implica na horizontalização das ligações do sujeito com os outros, pela tessitura de laços sociais e pela produção de obras no campo desses laços. Pode-se depreender disso tudo não só porque nessa última versão freudiana não existe oposição entre erotismo e sublimação, mas também porque a gestão do desamparo implica e se desdobra nos registros ético e político.

\section{Descontinuidade e Metapsicologia}

É necessário sublinhar, portanto, que a leitura que fazemos do discurso freudiano se funda no reconhecimento deste de uma descontinuidade fundamental e não de uma totalização sistemática. O discurso freudiano é marcado por uma ruptura crucial que reordenou, então, a sua direção teórica e seu rumo. Vale dizer, existe uma transformação decisiva naquele discurso que se desdobrou num outro estatuto para a teoria psicanalítica. Essa mudança teórica de estatuto da psicanálise se realizou no registro epistemológico pelos efeitos que pudemos ressaltar até agora.

Contudo, pode-se e deve-se perguntar neste momento de minha argumentação: por onde se operou essa transformação decisiva do estatuto epistemológico da psicanálise? Em qual registro teórico pode-se indicar o ponto 
de ruptura? É o que temos que responder em seguida. Para circunscrever a ruptura em questão, no nível epistemológico, é preciso evocar, antes, que nos seus primórdios a psicanálise seria, para Freud, um discurso científico. Era essa sua pretensão maior, como se sabe. Essa intenção implicou uma série de escolhas e de assunções de base pelo discurso psicanalítico. É justamente isso que precisa ser bem explicitado agora, para que se vislumbre por onde se processou a ruptura teórica e se realizou a descontinuidade.

Assim, a certeza freudiana inicial de uma harmonia sempre possível entre o registro da pulsão e o registro da civilização, pela qual esta dominaria e regularia aquela, se fundaria na perspectiva a priori de que as relações entre a força (Drang) pulsional e a representação (Verstellung) 4 seriam originárias, desde sempre dadas. Vale dizer, a articulação entre a força da pulsão e o objeto de satisfação seria desde sempre dada. $O$ circuito da pulsão seria regulado de maneira imanente, não obstante a concepção de que o objeto da pulsão seria aquilo que nessa seria o mais variável (FREUD, 1968). Isso não modifica em nada a noção de uma certa auto-regulação originária. A inserção da pulsão no campo da representação seria regulada da mesma maneira, na medida em que o objeto e o representante-representação da pulsão constituem as duas faces da mesma problemática: o primeiro enfatizando o registro do gozo, e o segundo, o do símbolo. Dessa maneira, o discurso psicanalítico seria algo da ordem da interpretação e da representação, pela mediação das quais poder-se-ia dominar a força da pulsão. Por esse viés, o sujeito poderia dominar o impacto da pulsão. Pode-se depreender, enfim, que não existiria uma mudança de essência entre o registro da força pulsional e o registro da civilização, na medida em que esta seria o suporte dos objetos do gozo e dos representantes.

Essa construção metapsicológica foi estabelecida pelo discurso freudiano, em 1905, nos "Três ensaios sobre a teoria da sexualidade" (FREUD, 1962, p. 56-58). Contudo, os princípios fundadores dessa construção foram elaborados anteriormente, por Freud, em seu "Projeto de uma psicologia científica", de 1895. Através desses princípios assumidos de forma tão precoce pelo discurso psicanalítico, pode-se melhor vislumbrar as escolhas realizadas por Freud. Com efeito, quando no preâmbulo do "Projeto de uma psicologia científica" foi enunciada a impossibilidade do princípio da inércia - porque, se fosse o caso, a vida seria impossível - e Freud o transformou no princípio da constância (FREUD, “Esquisse...”, 1973, p. 316-317), a construção auto-regulável do circuito pulsional estava caucionada, enquanto condição de possibilidade. Isso é evidente. Pode-se considerar que a solução tecida por Freud pressupõe 
uma hipótese vitalista, pela qual o registro da vida seria algo indubitável e fora de questão, sendo a construção do psiquismo uma derivação quase automática da ordem vital. A presença de metáforas vitalistas e a do ideal de homeostasia permeiam os textos freudianos iniciais. Por causa disso, o discurso psicanalítico podia ter a pretensão de ser da ordem da ciência e que, conseqüentemente, poderia, além disso, regular as relações entre a força da pulsão, seu objeto e seus representantes.

Além disso, como decorrência desses pressupostos, Freud acreditava ainda que existiria uma espécie de progresso do espírito humano, como afirmava a filosofia do Iluminismo na crença desta no poder da ciência para empreender a reforma do entendimento humano e da sociedade. Vale dizer, Freud acreditava como aquela que seria possível a produção da "felicidade humana" pela mediação do logos científico. Portanto, a cura das perturbações do espírito e do desamparo humano seria possível via psicanálise, uma das realizações maiores da razão científica. Disso se pode depreender que se encontram aqui os pressupostos teóricos sobre "A moral sexual 'civilizada' e a doença nervosa - fios tempos modernos", já que nesse ensaio se vislumbrava a possibilidade de uma harmonia entre o registro da pulsão e o da civilização.

Tudo isso se transformou radicalmente, no entanto, pelos fundamentos da segunda teoria das pulsões, com o enunciado do conceito pulsão de morte. Com efeito, pela mediação desse novo conceito de pulsão torna-se impossível a concepção de uma harmonia entre o registro da pulsão e o da civilização. Pelo viés da pulsão de morte, concebida agora como silenciosa e não inscrita originariamente no campo da representação, a harmonia com o registro da civilização não se torna mais possível. Portanto, no que tange à espécie humana, a vida seria algo a ser conquistado, um vir-a-ser e um destino possível, mas não um valor instituído de maneira originária. A vida, pois, seria um bem a ser produzido após a origem, já que a concepção de Freud agora é mortalista e antivitalista. A partir de agora a homeostasia é uma idéia impossível. Daí o malestar na civilização e o desamparo originário do sujeito. Porém, não basta apenas produzir a vida como um bem, em contraposição à morte originária. É preciso ainda reproduzi-la permanentemente, em toda a existência do sujeito. Daí, então, a idéia de gestão, para que o sujeito possa manter a vida enquanto possibilidade e um bem em aberto para si.

O discurso freudiano introduziu o significante destino, em seu ensaio metapsicológico sobre as pulsões, em 1915. Com efeito, em "Pulsões e destinos 
das pulsões" foi enunciado que as operações psíquicas do recalque e da sublimação seriam destinos das pulsões e não mecanismos originários (FREUD, 1968, p. 24). Para que aqueles fossem possíveis, necessário seria anteriormente que a força pulsional pudesse sofrer certas torções primordiais, como a "passagem do registro da atividade para o da passividade" e o "retorno sobre a própria pessoa" (FREUD, 1968, p. 24-32). Sem tudo isso, a construção da subjetividade seria impossível, na medida em que o movimento originário da força pulsional seria em direção à descarga. Pode-se entrever, aqui, o novo pressuposto freudiano de mortalismo e de antivitalismo, na medida em que o ensaio freudiano de 1915 já antecipava as condições de possibilidade do conceito de pulsão de morte, de 1920, ao formular a oposição de base entre a força pulsional, de um lado, e os objetos e representantes da pulsão, pelo outro. Enfim, o circuito pulsional não estaria ordenado desde a origem, como na formulação freudiana inicial, mas seria agora permanentemente empreendido pela subjetividade.

Porém, para isso o sujeito precisa do Outro, sem o qual o circuito pulsional não se ordenaria jamais, já que a força pulsional seria fadada à descarga, como indicado acima. Além disso, todo esse processo teria que ser não apenas produzido na origem mas também reproduzido por toda a existência do sujeito, na medida em que a pulsão é uma "força constante" (FREUD, 1968, p. 17-20). Vale dizer, o delineamento dos diferentes destinos da pulsão é um processo regular e repetido, mediante o qual o circuito pulsional assume diversas torções e se apresenta de diferentes maneiras. Como afirmamos, contudo, sem o Outro a ordenação do circuito pulsional seria algo da ordem do impossível, pois a força pulsional seguiria inevitavelmente a via da descarga. Com efeito, pela mediação do Outro seria promovida a ligação entre a força pulsional, os objetos e os representantes daquela. Sem o Outro, pois, o infante não poderia sobreviver, mesmo no registro da ordem vital.

A resultante dessa ligação seria a instauração dos princípios do prazer e da constância, já que nos primórdios existiria a primazia do princípio do Nirvana (FREUD, "Le problème...", 1973). Isso quer dizer que os princípios do prazer e da constância seriam derivados e secundários, produzidos pela transformação primordial do princípio do nirvana. Encontra-se justamente aqui a inovação freudiana face aos pressupostos do "Projeto de uma psicologia científica", já que nesse texto o prazer e a constância assumiam a função de princípios primordiais. 
Freud então empreendeu sua autocrítica logo no início do ensaio "O problema econômico do masoquismo", quando o princípio do Nirvana foi suposto como originário, em oposição ao do prazer. A autocrítica de Freud é bem evidente e de maneira literal. Assim, Freud enunciou que foi de forma "irrefletida que nós identificamos o princípio do prazer-desprazer com o princípio do nirvana" (FREUD, "Le problème...", 1973, p. 287-288). Em seguida, ele pôde concluir algo de seu erro: "Esta concepção não pode ser correta" (FREUD, "Le problème....", 1973, p. 282). Com isso, todos os pressupostos iniciais da metapsicologia freudiana foram reordenados em outras bases, porque, no novo contexto, o princípio do prazer e o erotismo seriam coisas a serem conquistadas pelo sujeito, para que se torne possível a ordem vital. A vida e a existência humana, em contraposição à ordem da natureza, somente seriam possíveis se o princípio do prazer e o erotismo se inscrevessem no organismo perpassado pelo mortalismo.

Porém, se é agora pela mediação do Outro que o mortalismo originário é transformado em prazer e erotismo, tornando viável a existência humana, pode-se depreender facilmente que se esboça aqui uma teoria da dívida simbólica. Com efeito, apenas nesse contexto a dívida simbólica se delineia como uma questão crucial para o sujeito, na medida em que este apenas se constitui, de fato e de direito, pela transformação realizada pelo Outro das forças pulsionais, de forma a delinear os diferentes destinos das pulsões. Encontra-se aqui, enfim, a condição de possibilidade de uma teoria da dívida simbólica em psicanálise, anteriormente inexistente.

Em contrapartida, pode-se evidenciar por essa leitura como o desamparo é originário, na medida em que o sujeito precisa do Outro para se produzir e reproduzir permanentemente enquanto tal. Sem o Outro, pois, não existiria o circuito pulsional, pois a força tomaria a direção de descarga. Conseqüentemente, pode-se bem depreender agora como a ética da "felicidade" da filosofia do Iluminismo não é mais possível no outro contexto teórico. Freud indicou isso desde o segundo capítulo de Mal-estar na civilização, de forma irrefutável, quando enunciou que, "tomado nesse sentido relativo, o único que parece realizável, a felicidade é um problema de economia libidinal individual” (FREUD, 1971, p. 29-30). Foi o arcabouço da ideologia do Iluminismo que ruiu aqui, que estava no fundamento no ensaio "A moral sexual 'civilizada' e a doença nervosa dos tempos modernos", como já indicado.

Contudo, pode-se sublinhar a extensão da autocrítica de Freud sobre sua versão inicial, sobre as relações harmônicas possíveis entre a pulsão e a 
civilização. Assim, as conclusões de Freud sobre a impossibilidade e os limites da "felicidade" humana foram retiradas a partir da crítica inicial que ele dirigiu a Romain Rolland sobre a inexistência do "sentimento oceânico", no primeiro capítulo de Mal-estar na civilização. Para circunscrever devidamente o alcance dessa crítica, é preciso reconhecer que a objeção freudiana sobre o "sentimento oceânico" visava não apenas a Romain Rolland, mas também à crença do primeiro Freud sobre as possíveis relações harmônicas entre os registros da pulsão e da civilização. Podemos afirmar que Mal-estar na civilização é uma crítica sistemática dos pressupostos freudianos iniciais, sustentados na "Moral sexual 'civilizada' e a doença nervosa dos tempos modernos", quando se acreditava ainda na harmonia entre a pulsão e a civilização. Com o desamparo originário do sujeito, tudo isso se tomou insustentável e uma outra leitura da inscrição do sujeito na civilização se tornou, então, possível.

Portanto, o discurso freudiano não sustentava mais a crença na idéia de "progresso do espírito humano", pela mediação do logos científico. O desamparo do sujeito seria o contraponto permanente à ideologia do progresso e ao cientificismo iluminista. Pode-se sublinhar a presença da crítica das idéias de civilização e de progresso no discurso freudiano já em 1915, num comentário agudo de Freud sobre os efeitos destruidores da Primeira Grande Guerra. Com efeito, em "Considerações atuais sobre a guerra e sobre a morte", Freud criticou o ideal civilizatório do progresso, baseado na razão científica, ao se confrontar com a devastação destruidora da guerra entretida pelos três maiores representantes da civilização ocidental, isto é, Alemanha, França e Inglaterra (FREUD, "Considérations...", 1995). A carnificina da guerra era a revelação evidente dos limites e das ilusões do progresso da dita civilização do Ocidente. Enfim, pode-se já entrever a desconstrução de Freud em sua leitura inicial sobre as relações entre pulsão e civilização, que atingirá o seu ponto culminante em Mal-estar na civilização.

Pode-se afirmar, ainda, que apenas nesse novo contexto teórico e crítico a problemática do desamparo foi inscrita no fundamento do sujeito e do pensamento psicanalítico, enquanto algo de ordem originária. Com efeito, não obstante o fato de que o significante desamparo tenha sido introduzido muito precocemente no discurso freudiano, desde o "Projeto de uma psicologia científica" (FREUD, "Esquisse...", 1973), existia aqui, contudo, a crença de que poderia ocorrer o domínio e a cura do desamparo do sujeito pela razão científica. Existe, no entanto, uma grande diferença entre os registros da palavra e do conceito, pois somente nos anos 15 e 20 é que o significante desamparo 
pôde adquirir a transcendência de um conceito. Para isso, enfim, necessário foi que a crença freudiana no poder do discurso científico, para promover o "progresso do espírito humano", tenha caído por terra e se espatifado em múltiplos fragmentos, evaporando-se como fumaça e ilusão.

Pode-se sublinhar, portanto, a presença de uma crítica na obra de Freud não da modernidade enquanto tal - o que seria ingênuo, já que a modernidade é uma produção da ordem da história -, mas dos impasses que a modernidade constituiu para o sujeito. Essa crítica se centrava naquilo que a ideologia do progresso e da razão cientificista prometeu no início do processo de modernização do Ocidente, no século XVIII. Vale dizer, essa crítica se fundava na impossibilidade de uma reforma do espírito humano e da sociedade, tendo como base a ideologia cientificista do progresso e da civilização. Reencontramos, aqui, o estilo trágico de pensamento do discurso freudiano no fim de seu percurso, que era não apenas ausente no início, como também será uma das fontes de discórdia da tradição psicanalítica pós-freudiana frente ao discurso freudiano.

\section{Natureza e Liberdade}

É preciso enunciar que, pela reflexão do processo civilizatório, Freud empreendeu efetivamente uma leitura sobre a modernidade, até mesmo porque a categoria de civilização foi constituída enquanto tal pela mo dernidade. Nos séculos XVIII e XIX, a problemática da civilização se transformou numa questão crucial para a Filosofia e as Ciências Humanas. Assim, é sempre a questão da modernidade que está em pauta para o discurso freudiano quando este toma a civilização como objeto de pesquisa e de reflexão. Portanto, a questão freudiana é se indagar sobre os efeitos da modernidade sobre o sujeito, quando este se funda nas pulsões como um de seus pólos.

Esta leitura sobre a modernidade se realizou numa linguagem psicanalítica, efetivamente. Situa-se, aqui, a novidade do discurso freudiano sobre aquela, seguramente. Isso porque Freud retomou os termos e as problemáticas em que a modernidade era representada desde o século XVIII, e deu a eles uma leitura fundada no sujeito e seus impasses. Foi por isso que Freud fez um recorte delineado pela idéia de conflito, no qual existiria uma oposição entre os pólos da pulsão e da civilização. Como vimos, esse conflito foi figurado mediante duas versões opostas, pela qual a primeira versão supõe 
uma harmonia possível entre as polaridades, em que uma delas absorve e incorpora a outra nos seus termos; e a segunda supõe a não-conciliação possível. Pela segunda versão, o sujeito é obrigado a realizar a gestão do conflito nos campos político e social, regulado que seria pelos laços sociais.

Porém, se o discurso freudiano retomou os termos de uma problemática já existente sobre a modernidade, nos séculos XVIII e XIX, é necessário, agora, explicitar a que categorias Freud se referia quando as transvestiu numa linguagem psicanalítica. Com efeito, o discurso freudiano retomou a oposição entre a categoria de natureza e a de liberdade que marcaram a problemática da modernidade desde seus primórdios. Nessa oposição, a liberdade caracterizaria o valor construído pela modernidade, enquanto o registro da natureza seria o traço da tradição e de auto-regulação presente no mundo prémoderno. Como se sabe, o registro da liberdade foi a condição de possibilidade para se pensar a transformação do mundo pré-modemo pelas individualidades no nível político e no nível social. Além disso, foi a condição para se acreditar numa reforma da natureza das individualidades pela razão científica. Finalmente, pelo pólo da liberdade a idéia de uma história humana seria possível na medida em que as relações do sujeito com o registro da temporalidade se transformariam.

Assim, a história toma o lugar da teodicéia na reflexão sobre os destinos dos homens na ordem social. Da mesma forma, a razão científica, atributo maior que seria da autonomia e da liberdade humanas, assumiria o lugar do sujeito da inteligência divina. Tudo isso se desdobra nos conceitos de artífice e de artificialismo que passam a marcar as produções humanas, já que, como promoções do pólo da liberdade, se oporiam ao pólo da natureza. Constitui-se, aqui, a categoria de civilização como desdobramento do pólo da liberdade. Além disso, pela liberdade e pela razão científica o sujeito moderno assume uma configuração prometéica, desafiando os deuses e a regulação da natureza pela ética religiosa.

Todas essas problemáticas perpassam a construção da problemática da modernidade, representada pela polaridade entre a natureza e a liberdade. Aquela problemática foi pensada tanto pela tradição filosófica de então recordem-se aqui, como alusão, as filosofias de Hobbes, Locke, Rousseau, Kant, Hegel, Marx e o Iluminismo - quanto pelos discursos das Ciências Humanas, que se constituíram nesse contexto histórico. Foram, pois, esses termos e problemáticas que o discurso freudiano retomou para desenvolver a sua interpretação sobre a modernidade. 
A pontuação que realizamos agora não implica afirmar que Freud tenha tido um conhecimento filosófico aprofundado e exaustivo dessas diferentes tradições teóricas. Absolutamente. Não é o que pensamos. Porém, as questões levantadas pelas diferentes tradições teóricas e as soluções que estas deram para tais indagações estavam presentes nos campos discursivo e cultural de Freud. Foi daí que ele as retirou, para desenvolvê-las numa perspectiva psicanalítica, buscando empreender uma leitura original fundada na oposição entre pulsão e civilização. Foi esta a matéria-prima das elaborações de Freud, que repensou então a modernidade pelos eixos do sujeito e da pulsão.

Assim, pode-se dizer que a natureza dos antigos foi pensada pelo registro da pulsão e que a liberdade dos modernos, pelo registro da civilização. Em sua versão inicial, o discurso freudiano acreditava que, pela auto-regulação da natureza, seria possível ainda uma harmonia entre o registro da civilização e o da liberdade. $O$ determinismo cientificista do primeiro discurso freudiano seria a revelação mais eloqüente desse encaminhamento teórico. Contudo, em sua versão final o discurso freudiano não acreditava mais em tal harmonia, já que esta não mais seria possível. Os conceitos de desamparo e de mal-estar na civilização revelam a emergência da fragilidade humana num mundo onde não seria mais possível pensar na auto-regulação da natureza. Da mesma forma, o indeterminismo que marca o segundo discurso freudiano, do ponto de vista epistemológico, seria a evidência maior dessa nova elaboração teórica.

Pela primeira versão não existiria rigorosamente o desamparo do sujeito, ou aquele seria curável, pois a auto-regulação da natureza protegeria a subjetividade. Entretanto, pela segunda leitura o desamparo seria não apenas inevitável mas também incurável, já que não existiria mais qualquer proteção originária para o sujeito. Por isso mesmo, impõe-se ao sujeito a exigência de gestão do mal-estar e do desamparo, pelo registro horizontalizado dos laços sociais. Nesse contexto, a ética da "felicidade" humana, sustentada na primeira versão de Freud e no Iluminismo, se toma problemática enquanto finalidade auto-engendrada pela regulação natural.

Pode-se depreender que a leitura freudiana do mal-estar na modernidade é o contraponto psicanalítico das leituras de Weber e de Heidegger sobre a mesma problemática. Se o primeiro enunciou o pressuposto do desencantamento do mundo como condição da modernidade (WEBER, 1966) e o segundo se fundou na morte de Deus para se referir a esse desencantamento (HEIDEGGER, 1962, p. 69), trata-se sempre, nos dois discursos, de interpretar 
a problemática da modernidade. O discurso do último Freud indica como a racionalização do mundo pela ciência e o correlato esvaziamento dos deuses que encantavam o mundo produzem no sujeito um desamparo originário e inevitável. Além disso, se o mundo sem Deus de Heidegger indica a perda de fundamento do mundo a que se referia Nietzsche (HEIDEGGER, 1971), podese dizer que, em sua versão inicial, Freud acreditava ainda na regulação possível do homem dividido pela auto-regulação da natureza. O último Freud, entretanto, não acreditava mais nessa possibilidade, já que o sujeito dividido e sem qualidades (MUSIL, 1980) é destinado ao desamparo e ao mal-estar. Enfim, pode-se dizer que a descoberta psicanalítica do inconsciente é a condensação disso tudo, uma metáfora das novas modalidades de inserção do sujeito no mundo. Enfim, da mesma forma como Weber e Heidegger, Freud forjou uma leitura da modernidade e de seus impasses, pela reinvenção do conflito entre a natureza dos antigos e a liberdade dos modernos, segundo os cânones da linguagem conceitual da psicanálise.

\section{Decepção, Promessa e Ilusão}

Podemos agora retomar a problemática da psicanálise na atualidade, isto é, sua crise no mundo da pós-modernidade. Assim, se aquela perdeu hoje o prestígio e o poder simbólico que ela usufruía até bem recentemente, isso pode ser considerado por diferentes pontos de vista. Antes de mais nada, o mundo e o desejo das pessoas buscam sempre a harmonia possível entre as demandas das pulsões e a efetividade de sua satisfação. Entre natureza e liberdade, o conflito continua a desestabilizar o sujeito, que busca uma harmonia ideal e um equilíbrio possível. Isso tudo para afastar, custe o que custar, o desamparo produzido por esse conflito, e para dominar o mal-estar social produzido pelo desamparo.

Como sabemos, a psicanálise prometeu tudo isso ao mundo no início do percurso de Freud. Por isso mesmo, a psicanálise se transformou num fascínio irresistível na modernidade, e seduzia a todos na medida em que poderia realizar a ilusão das individualidades em busca do apaziguamento do desamparo e do domínio do mal-estar social. A psicanálise pós-freudiana ainda insistiu nessa tecla, alimentando o lugar mítico da psicanálise na modernidade, não obstante a perspectiva trágica do último Freud. Porém, a promessa não se realizou, esvaziando o poder da sedução e evaporando o charme fascinante do discurso psicanalítico. Isso porque, apesar da sedução, o desamparo se mantinha incurável 
e aumentava, em muito, o mal-estar social. Enfim, o sonho psicanalítico se esfacelou pelo impacto da luminosidade das evidências, pois o mal-estar e o desamparo estavam sempre lá, espreitando as individualidades.

Contudo, com a decepção produzida pela promessa ilusória da psicanálise, outros prestidigitadores ocuparam o lugar deixado por esta e relançaram as mesmas promessas. Isso porque, é óbvio, as subjetividades demandam ainda uma cura para o desamparo e o mal-estar. A ilusão continua lá, intacta, nos corações e nas mentes dos indivíduos. Por isso mesmo, a psicofarmacologia, as neurociências e o cognitivismo vêm à cena para restabelecer a mesma crença e a ilusão das subjetividades, de que tudo isso seria ainda possível. Esses saberes, com suas tecnologias específicas, vêm ao mundo para fazer a mesma promessa e alimentar a mesma ilusão de harmonia possível, como acreditava ainda o primeiro Freud. Tanto como este, tudo seria possível em nome da razão científica.

É preciso sublinhar, ainda, os efeitos de tudo isso na comunidade psicanalítica. Diante da decepção que a psicanálise provocou, diante do engodo da promessa não-realizada, aquela comunidade passa a ser permeada pelo desamparo e pelo mal-estar. Esses passam a invadir o mundo psicanalítico, que se obceca com isso. A reação de uma parcela da comunidade analítica, em contrapartida, é ainda querer acreditar na cura do mal-estar e do desamparo. Pasmem, se quiserem. Porém, é isso mesmo que ocorre.

E o que faz essa parcela da comunidade psicanalítica com isso? Transforma a face do discurso psicanalítico, ao silenciar sua especificidade, desvitalizando-a. Com isso, a segunda versão freudiana sobre as relações entre sujeito e civilização foi esquecida novamente, e lançada para bem longe. Isso porque esta evoca permanentemente o desamparo e evidencia o mal-estar no social. Para se contraporem à gestão política que isso implica, reconstroem uma outra versão tecnológica da psicanálise. De que maneira? Pela bricolagem entre o discurso psicanalítico, as neurociências e o cognitivismo. Um monstro epistemológico foi assim colocado em cena, balizando pesquisas em laboratórios de psicanálise e em associações psicanalíticas, tanto no norte quanto no sul do Equador.

Como conseqüência, o mal-estar agora se faz presente de uma outra maneira na comunidade analítica, invadida pela bricolagem teórica e clínica da psicanálise, na medida em que aquela não pode se defrontar radicalmente com o desamparo. Esse é nosso ponto de chegada, que revela a face mais hedionda 
e crítica da crise da psicanálise. De nossa parte, não acreditamos que a psicanálise possa efetivamente sobreviver, marcada por sua especificidade nos registros teórico e ético, se ela não pode reconhecer o desamparo do sujeito e do mal-estar social decorrente na dita pós-modernidade. Não será pela bricolagem com as neurociências e o cognitivismo triunfantes, prometendo a harmonia entre a natureza e a liberdade, que a psicanálise sairá de sua crise atual. É preciso retomar o último Freud, retirando dele as consequiências políticas que o desamparo originário impõe, para realizar a gestão do mal-estar no social.

\section{Referências}

BIRMAN, J. Figuras do analista no cinema. In: BIRMAN, J. Por uma estilística da existência. São Paulo: Editora 34, 1996.

CASTEL, F.; CASTEL, R.; LOVELL, A. La société psychiatrique avancée: le modèle américain. Paris: Grasset, 1979.

FREUD, S. Trois essais sur la théorie de la sexuaiité. Paris: Gallimard, 1962 [1905], Primeiro Ensaio.

Pulsions et destins des pulsions. In: FREUD, S. Métapsychologie. Paris: Gallimard, 1968 [1915].

. La morale sexuelle "civilisée" et la maladie nerveuse des temps modernes. In: FREUD, S. La vie sexuelle. Paris: Presses Universitaires de France, 1969 [1908].

. Malaise dans la civilisation. Paris: Presses Universitaires de France, 1971 [1929].

Esquisse d'une psychologie scientifique. In: FREUD, S. La naissance de Ia psychanalyse. Paris: Presses Universitaires de France, 1973 [1895]. Primeira Parte, Capítulo 1.

. Le problème économique du masochisme. In: FREUD, S. Névrose, psychose et perversion. Paris: Presses Universitaires de France, 1973 [1924].

. Inhibition, symptôme et angoisse. Paris: Presses Universitaires de France, 1973. [1926].

. Nouvelles conférences de l'introduction à Ia psychanaIyse. XXXII Conferência. Paris: Gallimard, 1984 [1932]. 
L'analyse avec fin et l'analyse sans fin In: FREUD, S. Résultats, idées, problémes. Paris: Presses Universitaires de France, 1986 [1937], V. II. . Considérations actuelles sur la guèrre et sur la mort In: FREUD, S. Essais de psychanalyse. Paris: Payot, 1995 [1915].

Au-delà du principe de plaisir. In: FREUD, S. Essais de psychanalyse. Paris: Payot, 1995 [1920].

HEIDEGGER, M. Chemins qui ne menènt nulle part Paris: Gallimard, 1962. . Nietzsche. Paris: Gallimard, 1971, V. I e II.

MUSIL, R. O homem sem qualidades. Lisboa: Livros do Brasil, 1980, V. I, II e III.

TURKE, S. La irrupción del psicoanálisis en Francia. Buenos Ayres: Paidós, 1993.

WEBER, M. L'éthique protestante et l esprit du capitalisme. Paris: Plon, 1966. 


\section{NOTAS}

${ }^{1}$ Conferência realizada em Paris, no Palais de Luxembourg, em 15 de janeiro de 1998, no Colloque International Transdisciplinaire, com o tema "Dérives et Mutation du Lien-passages: Situations du Sujet et Modernités”. Colóquio organizado pela Association Rencontres d' Anthropologie, Psychanalyse et Recherches sur le Processus de Socialisation (ARAPS), e pela Revue Psychanalyse, Traversées, Anthropologie et Histoire (PTAH). Publicado em Physis, v. 8. n. 1, 1998, p. 123-144.

${ }^{2}$ Psicanalista, professor titular do Instituto de Psicologia da Universidade Federal do Rio de Janeiro, professor adjunto do Instituto de Medicina Social da Universidade do Estado do Rio de Janeiro.

${ }^{3}$ Sobre a articulação teórica entre modernização do social e a constituição do movimento psicanalítico, ver Turke (1993).

${ }^{4}$ Sobre esses conceitos, ver Freud (1968).

\section{ABSTRACT}

The Discontent in Modernity and Psychoanalysis: Social-Proof Psychoanalysis

The article aims at showing the presence of two opposing theoretical discourses in Freud, in what concerns the relationship between the subject and modemity. It intends to demonstrate that in its second version, developed in Malaise dans ia civilisation, the analytical discourse achieved a systematic critical review of its initial version outlined in "La morale sexuelle 'civilisée' et la maladie nerveuse des temps modemes". Through constructing the concepts of discontent and distress, the Freudian discourse thus made psychoanalysis social-proof. In addition, it indicates that psychoanalysis was able to build a reading of modemity other than those made by Weber and Heidegger. Finally, this joumey also aims at thinking over the present crisis of psychoanalysis within the new conditions of discontent in modemity.

Key words: Discontent; distress; sublimation. 